\title{
Ratcheting-Fatigue Behavior of Harmonic-Structure-Designed SUS316L Stainless Steel
}

\author{
Yang Song ${ }^{1}$, Zhe Zhang ${ }^{2,3, *}$, Hantuo Ma ${ }^{2}$, Masashi Nakatani ${ }^{4}$, Mie Ota Kawabata ${ }^{4}$ and Kei Ameyama ${ }^{4}$ (ID \\ 1 Tianjin Key Laboratory for Advanced Mechatronic System Design and Intelligent Control, \\ National Demonstration Center for Experimental Mechanical and Electrical Engineering Education, \\ School of Mechanical Engineering, Tianjin University of Technology, Tianjin 300384, China; \\ songyang2661@sina.com \\ 2 School of Chemical Engineering and Technology, Tianjin University, Tianjin 300350, China; \\ hantuoma@hotmail.com \\ 3 Tianjin Key Laboratory of Chemical Process Safety and Equipment Technology, Tianjin 300350, China \\ 4 Department of Mechanical Engineering, Faculty of Science and Engineering, Ritsumeikan University, \\ Shiga 525-8577, Japan; rm005034@ed.ritsumei.ac.jp (M.N.); mie-ota@fc.ritsumei.ac.jp (M.O.K.); \\ ameyama@se.ritsumei.ac.jp (K.A.) \\ * Correspondence: zhe.zhang@tju.edu.cn
}

Citation: Song, Y.; Zhang, Z.; Ma, H.; Nakatani, M.; Kawabata, M.O.; Ameyama, K. Ratcheting-Fatigue Behavior of

Harmonic-Structure-Designed SUS316L Stainless Steel. Metals 2021,

11, 477. https://doi.org/

$10.3390 /$ met11030477

Academic Editor: Eric Hug

Received: 25 January 2021

Accepted: 5 March 2021

Published: 13 March 2021

Publisher's Note: MDPI stays neutral with regard to jurisdictional claims in published maps and institutional affiliations.

Copyright: (c) 2021 by the authors. Licensee MDPI, Basel, Switzerland. This article is an open access article distributed under the terms and conditions of the Creative Commons Attribution (CC BY) license (https:/ / creativecommons.org/licenses/by/ $4.0 /)$.

\begin{abstract}
Stainless steels with harmonic-structure design have a great balance of high strength and high ductility. Therefore, it is imperative to investigate their fatigue properties for engineering applications. In the present work, the harmonic-structured SUS316L stainless steels were fabricated by mechanical milling (MM) and subsequent hot isostatic pressing (HIP) process. A series of ratchetingfatigue tests were performed on the harmonic-structured SUS316L steels under stress-control mode at room temperature. Effects of grain structure and stress-loading conditions on ratcheting behavior and fatigue life were investigated. Results showed that grain size and applied mean stress had a significant influence on ratcheting-strain accumulation and fatigue life. Owing to the ultrafine grained structure, tensile strength of the harmonic-structured SUS316L steels could be enhanced, which restrained the ratcheting-strain accumulation, resulting in a prolonged fatigue life. A higher mean stress caused a faster ratcheting-strain accumulation, which led to the deterioration of fatigue life. Moreover, a modified model based on Smith-Watson-Topper (SWT) criterion predicted the ratcheting-fatigue life of the harmonic-structured SUS316L steels well. Most of the fatigue-life points were located in the 5 times error band.
\end{abstract}

Keywords: stainless steel; harmonic structure; ratcheting; fatigue; fatigue-life prediction

\section{Introduction}

Austenitic stainless steels have excellent mechanical properties and corrosion resistance, and are often used as structural materials in petrochemical equipment, nuclear equipment, and medical equipment [1-3]. Therefore, it is imperative to realize high strength and high ductility in stainless steels for structural safety. Usually, these types of equipment are often subjected to cyclic loading in service. Thus, cyclic deformation and fatigue properties of stainless steels need to be considered [4-6].

In recent years, structural materials with heterogenous microstructures have been proposed to achieve excellent mechanical properties and good fatigue resistance [7-15]. Mechanical properties and deformation mechanisms of some typical heterogenous microstructures, such as gradient nanograined (GNG) structure [9-11], lamellar structure [12-14], hierarchical and laminated grains and twins structure [15], and harmonic structure [16,17], have been investigated. As indicated in Figure 1a, the conventional bimodal structure has an irregular coarse grain (CG) and ultrafine grain (UFG) distribution. By contrast, harmonic structure has a regular bimodal grain-size distribution, whereas UFG structure (shell) exhibits a three-dimensional, continuously connected network structure (Figure 1b). 
The regular network structure could relieve strain localization during tensile deformation, which causes an extra strain hardening. Therefore, the harmonic-structure-designed materials exhibit a superior strength-ductility synergy [18-23].
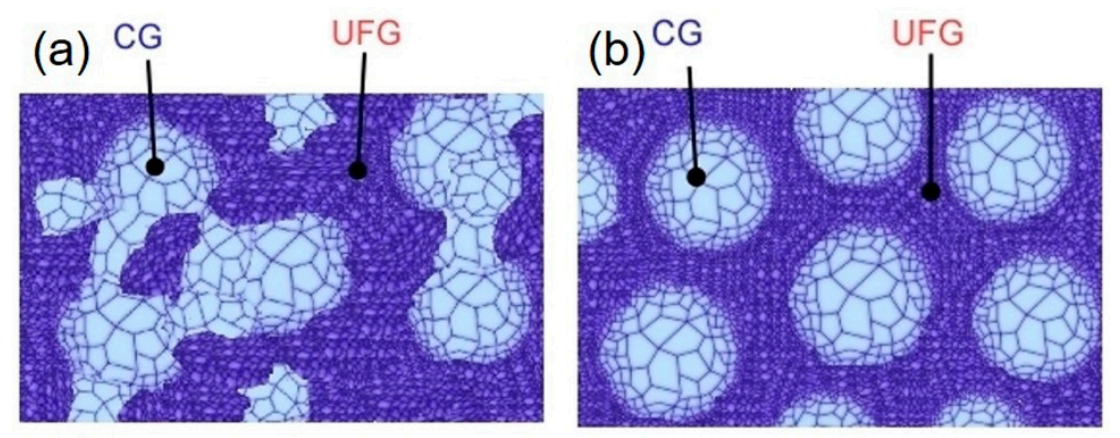

Figure 1. Schematic of (a) bimodal structure and (b) harmonic structure.

For engineering applications in service, the cyclic response and fatigue properties of heterogenous-structured stainless steels have been studied in the past decades. GNG SUS316L steels demonstrated a superior balance of high strength and large uniform elongation, as well as good fatigue resistance. Due to the increased tensile strength by GNG surface layer, high-cycle fatigue resistance could be improved in GNG steels compared to CG or UFG steels. By contrast, it is remarkable that abnormal grain coarsening could suppress surface roughening and fatigue cracking. Thus, low-cycle fatigue resistance was also improved in GNG materials $[9,10]$. It was found that lamellar structure impeded fatigue-crack growth, which restrained fatigue-crack growth rates $[13,14]$. Therefore, the lamellar-structured steels also demonstrated good fatigue resistance. Furthermore, the steels with hierarchical and laminated grains and twins also induced a friction stress that acted on the crack surface and decelerated fatigue-crack opening and growth [15]. The high-cycle fatigue properties and fatigue-crack growth behavior of harmonic-structured SUS316L steels have been investigated [24,25]. Fatigue limits of the harmonic-structure SUS316L steels were higher than that of the CG SUS316L steels, which was related to the enhanced tensile strength [24]. As expected, the UFG structure had worse crack-growth resistance than the CG structure. Therefore, the harmonic-structured 316L steels had higher fatigue-crack growth rates and a lower threshold stress intensity factor range for crack growth $\left(\Delta K_{t h}\right)$ compared to the homogeneous CG SUS316L steels. Fatigue cracks tended to propagate along UFG network structure in harmonic-structured SUS316L steels $[25,26]$.

As mentioned, stainless steels are often used as structural materials in thin-wall piping systems, which are often subjected to cyclic loading and alternating temperature or internal pressure, especially during start/stop operation. Therefore, pipelines are subjected to an asymmetric stress cycling, which can cause an accumulation of plastic strain known as ratcheting strain [27-31]. For example, in the early 1990s, the ratcheting-fatigue behavior of nuclear pipes and its detrimental effect on the nuclear-reactor structure were contained in the American ITER design code and ASME NB 32xx code [27]. As reported, mean stress had a much higher influence on ratcheting-strain accumulation than stress amplitude or stress-loading rate. Therefore, the effects of mean stress on ratcheting strain and low-cycle fatigue life were investigated in stainless steels. In general, a larger mean stress induced a rapid -train accumulation, resulting in deterioration of fatigue life. Moreover, many stress-based criteria have been proposed to correct the effect of mean stress on fatigue-life prediction in the past decades, such as the Goodman criterion, Gerber criterion, SmithWatson-Topper (SWT) criterion, and so on. It also has been reported that the models based on the SWT criterion possessed a higher prediction accuracy for ratcheting-fatigue life of steels subjected to asymmetrical stress cyclic loading [4,28]. However, comprehensive understanding of ratcheting behavior and fatigue-life prediction for harmonic-structured stainless steels still remains unclear. 
In the present work, the ratcheting-fatigue properties of the harmonic-structured SUS316L steels were investigated. The effect of grain structure and applied mean stress on ratcheting strain and fatigue life are revealed. Moreover, a modified model based on the SWT criterion is proposed for the prediction of fatigue life of harmonic-structured SUS316L steels.

\section{Materials and Experiments}

SUS316L stainless steels with a harmonic-structure topology were fabricated using horizontal ball-milling and hot isostatic pressing (HIP) processes. The chemical composition of the SUS316L gas-atomized powders is shown in Table 1. The powder features, mechanical milling, and sintering process were introduced in our previous study [32]. In the present work, gas-atomized SUS316L steel powders were milled at room temperature for $10 \mathrm{~h}$ and $30 \mathrm{~h}$. The compacts were sintered from initial powders and milled powders using a hot isostatic pressing (HIP) process with a pressure of $200 \mathrm{MPa}$ at $900^{\circ} \mathrm{C}$ for $4 \mathrm{~h}$. The compact sintered from initial powders was denoted as the MM0h compact. The compacts sintered from milled powers for $10 \mathrm{~h}$ and $30 \mathrm{~h}$ were denoted as the MM10h compact and the MM30h compact, respectively. The grain structures of sintered compacts are shown in Figure 2. It can be seen in Figure 2a that the MM0h compact had a partial harmonic structure, which was attributed to an irregular initial powder size ranging from $1 \mu \mathrm{m}$ to $20 \mu \mathrm{m}$. As indicated in Figure $2 b, c$, it was seen that the volume fraction of ultrafine grains increased as the mechanical milling time increased from $10 \mathrm{~h}$ to $30 \mathrm{~h}$, resulting in a reduced grain size. Moreover, a continuous UFG network structure was observed, which indicated that a harmonic structure was produced in the compacts sintered from milled powders. Grain size and its volume fraction of sintered compacts are presented in Table 2. As indicated in Table 3, both yield strength (YS) and ultimate tensile strength (UTS) were enhanced with decreasing grain size [32].

Table 1. Chemical composition of SUS316L gas-atomized powders (mass\%).

\begin{tabular}{ccccccccc}
\hline $\mathbf{C}$ & $\mathbf{S i}$ & $\mathbf{M n}$ & $\mathbf{P}$ & $\mathbf{S}$ & $\mathbf{N i}$ & $\mathbf{C r}$ & $\mathbf{M o}$ & $\mathbf{F e}$ \\
\hline 0.018 & 0.9 & 1.07 & 0.032 & 0.017 & 12.44 & 17.31 & 2.11 & Bal. \\
\hline
\end{tabular}
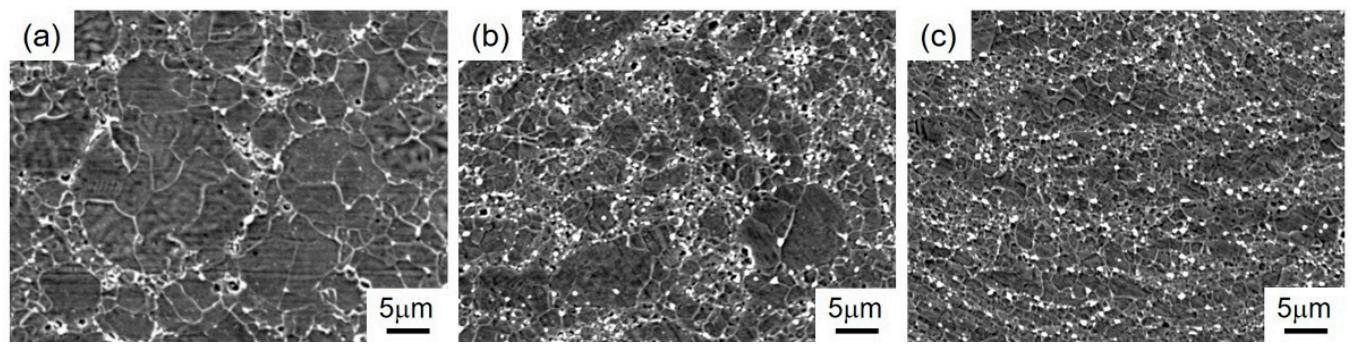

Figure 2. Microstructure of sintered SUS316L compacts: (a) MM0h compact; (b) MM10h compact; (c) MM30h compact.

Table 2. Grain size of harmonic-structured SUS316L compacts.

\begin{tabular}{ccccc}
\hline Materials & $\begin{array}{c}\text { Core Grain Size } \\
\text { (CG), } \mathbf{~ m m}\end{array}$ & Core Fraction & $\begin{array}{c}\text { Shell Grain } \\
\text { Size (UFG), mm }\end{array}$ & Shell Fraction \\
\hline MM0h & 3.94 & $86.7 \%$ & 1.28 & $13.3 \%$ \\
MM10h & 1.84 & $73.5 \%$ & 0.64 & $26.5 \%$ \\
MM30h & 1.16 & $45.5 \%$ & 0.42 & $54.5 \%$ \\
\hline
\end{tabular}


Table 3. Loading conditions and fatigue life of ratcheting-fatigue tests for harmonic-structured SUS316L steels.

\begin{tabular}{|c|c|c|c|c|}
\hline Materials & $\begin{array}{c}\text { Mean Stress } \sigma_{m} \\
(\mathrm{MPa})\end{array}$ & $\begin{array}{c}\text { Stress Amplitude } \\
\sigma_{a}(\mathrm{MPa})\end{array}$ & $\begin{array}{l}\text { Stress Rate } \\
(\mathrm{MPa} / \mathrm{s})\end{array}$ & $\begin{array}{c}\text { Fatigue Life } N_{f} \\
\text { (Cycles) }\end{array}$ \\
\hline \multirow{3}{*}{ MMOh } & 300 & & & 29,774 \\
\hline & 400 & & & 14,440 \\
\hline & 450 & & & 432 \\
\hline \multirow{2}{*}{ MM10h } & 400 & 300 & 300 & 17,854 \\
\hline & 450 & & & 14,666 \\
\hline \multirow{2}{*}{ MM30h } & 400 & & & 41,227 \\
\hline & 450 & & & 18,599 \\
\hline
\end{tabular}

Figure 3 shows the setup of the ratcheting-fatigue test. As shown in Figure 3a, fatigue tests were conducted with an in-situ fatigue-testing machine (IBTC-5000, CARE, Tianjin, China) under stress-control mode at room temperature. A triangle waveform stress loading with a constant loading rate $300 \mathrm{MPa} / \mathrm{s}$ was carried out. In order to prevent buckling of the specimen, the stress ratio $R$ was more than zero. Displacement of gauge area was recorded by a noncontact CCD camera (Figure 3c). The typical stress-strain response is shown in Figure $3 b$. The dimensions of specimens for the ratcheting fatigue tests are shown in Figure 3b. The specimens were ground using a 5000 grit $\mathrm{SiC}$ paper before fatigue tests. The ratcheting strain $\left(\varepsilon_{r}\right)$ is defined as:

$$
\varepsilon_{r}=\frac{1}{2}\left(\varepsilon_{\max }+\varepsilon_{\min }\right)
$$

where $\varepsilon_{\max }$ and $\varepsilon_{\min }$ are demoted as the maximum strain and minimum strain in each cycle, respectively. The loading conditions of ratcheting fatigue tests and observed fatigue life are listed in Table 3. Some high-cycle fatigue data of the harmonic-structured $316 \mathrm{~L}$ steels from our previous study were obtained [24]. These data were also used to analyze the fatigue-life-prediction model of harmonic-structured $316 \mathrm{~L}$ steels. Grain structure and fatigue fracture surface were examined by field emission-scanning electron microscopy (FE-SEM, SU4800, Tokyo, Japan) at $15 \mathrm{kV}$.

(a)

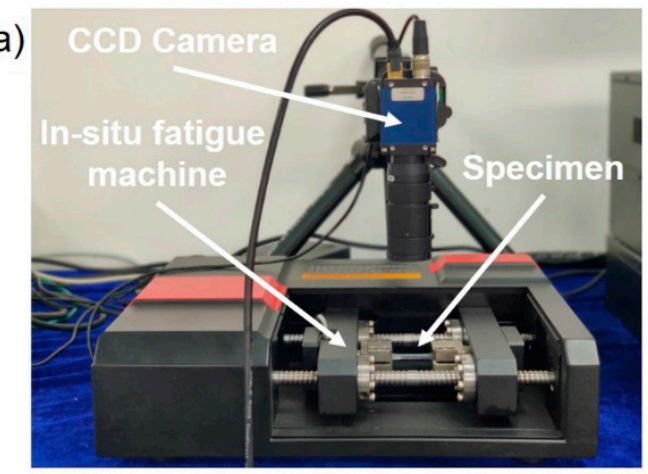

(b)

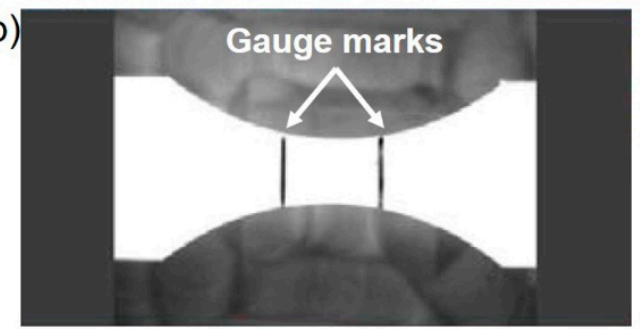

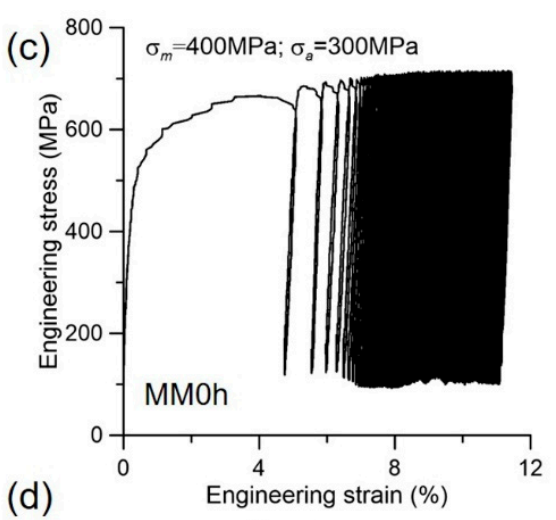

(d)

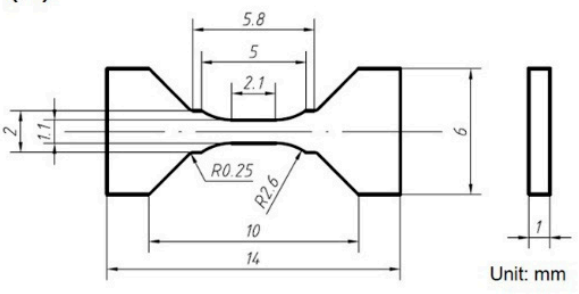

Figure 3. (a) Experiment setup; (b) typical stress-strain response; (c) displacement of gauge area measurement; (d) dimensions of specimen for ratcheting-fatigue test. 


\section{Results and Discussion}

\subsection{Effects of Grain Structure on Ratcheting-Fatigue Behavior of Harmonic-Structured} SUS316L Steels

Figure 4 summarizes the effects of grain structure on ratcheting strain and fatigue life of the harmonic-structured SUS316L steels. As shown in Figure 4a,b, the ratcheting-fatigue tests of the harmonic structured SUS316L steels with different grain sizes were performed under the same loading condition $\left(\sigma_{m}=400 \mathrm{MPa}, \sigma_{a}=300 \mathrm{MPa}\right)$. It is noted that the grain structure had a great influence on both ratcheting strain and fatigue life. Figure $4 \mathrm{~b}$ shows the ratcheting strain versus $N / N_{f}$. It can be seen in Figure $4 \mathrm{~b}$ that the ratcheting strain accumulated rapidly in the early stage of cyclic deformation. The ratcheting strain of MM0h compact was approximately $10.6 \%$ at $0.1 N_{f}$. By contrast, the values were approximately $4.2 \%$ and $2.5 \%$ for the MM10h compact and the MM30h compact, respectively. It is noteworthy that the ratcheting strain decreased with decreasing grain size. Subsequently, the increment of ratcheting strains was stable between $0.1 N_{f}$ and $0.8 N_{f}$. At the final stage, the ratcheting strain increased rapidly to failure as $N / N_{f}$ was over than 0.8 . Moreover, the number of cycles to failure for the MM0h compact was 14,440 cycles, while the values for the MM10h compact and the MM30h compact were 17,854 cycles and 41,227 cycles, respectively. It was indicated that the harmonic-structured SUS316L steel with lower grain size possessed a longer fatigue life. A similar tendency was also observed in the results shown in Figure $4 \mathrm{c}, \mathrm{d}$ at $\sigma_{m}=450 \mathrm{MPa}, \sigma_{a}=300 \mathrm{MPa}$.
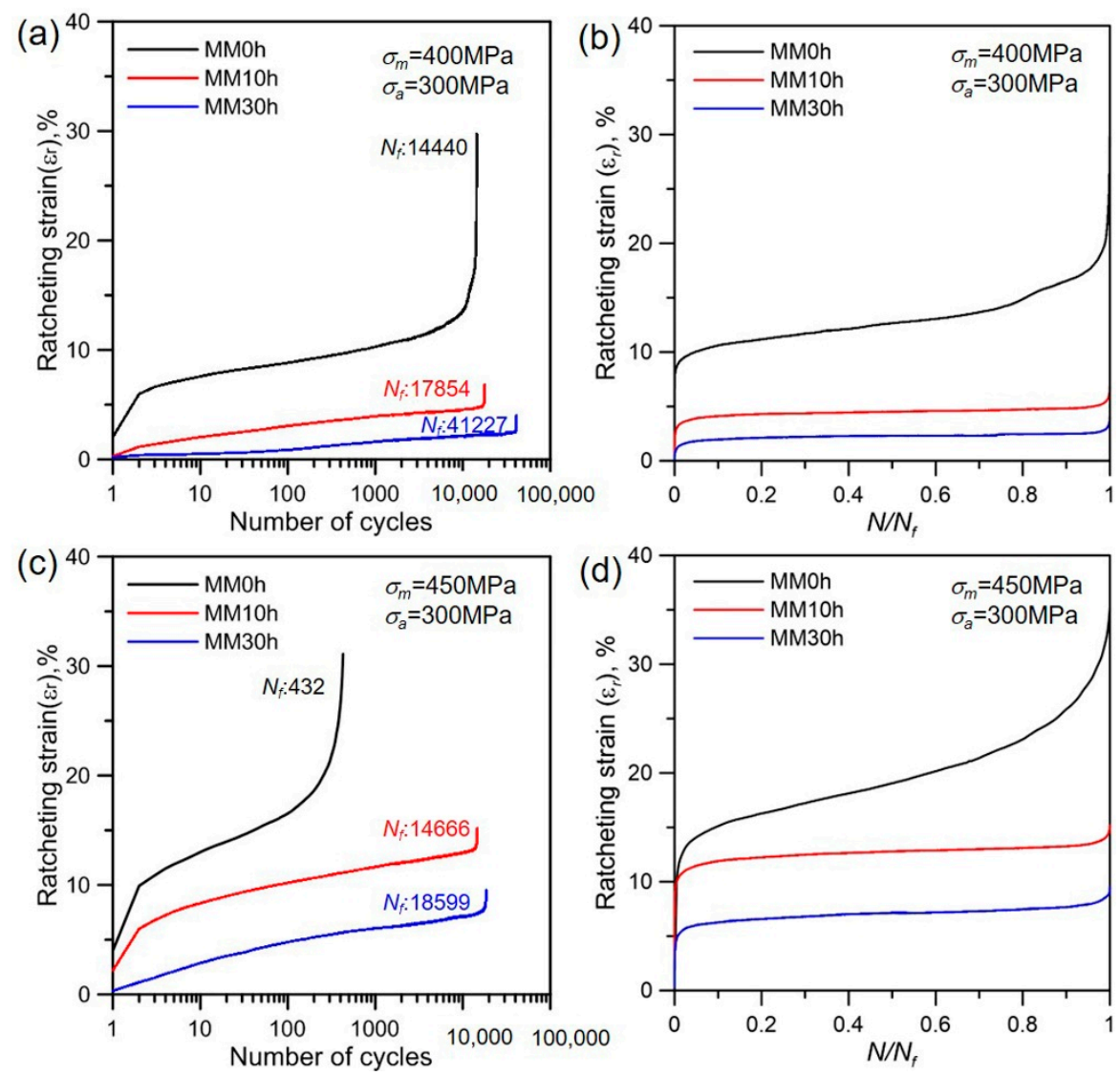

Figure 4. Effects of grain structure on fatigue life $(\mathbf{a}, \mathbf{c})$ and ratcheting strain $(\mathbf{b}, \mathbf{d})$ of harmonicstructured SUS316L steels: $(\mathbf{a}, \mathbf{b}) \sigma_{m}=400 \mathrm{MPa}, \sigma_{a}=300 \mathrm{MPa}$; (c,d) $\sigma_{m}=450 \mathrm{MPa}, \sigma_{a}=300 \mathrm{MPa}$.

As indicated in Figure 4, the variation of ratcheting strain could be divided into three stages, which appeared to be creep strain. It is known that creep strain is caused by microvoid formation and grain boundary sliding. However, the mechanism of ratcheting strain is different. Specifically, ratcheting strain is thought to be related to the progressive 
development of plastic deformation. Active dislocations decrease in the early stage of cyclic deformation, which leads to a rapid ratcheting strain accumulation. The dislocation structure becomes stable in the following stage, resulting in a stable ratcheting-strain rate. At the last stage, due to microcracks or main fatigue-crack growth, the true stress level increases, resulting in an accelerated ratcheting-strain rate [33].

Owing to the shell region in harmonic-structured SUS316L steels, the strength increases with increasing shell volume fraction. Moreover, the ratcheting strain is determined by accumulative plastic deformation. Therefore, it can be seen in Figure 4 that the ratcheting strains were restrained in the MM10h compact and the MM30h compact compared to the MMOh compact. A lower strength produced a higher plastic strain under the same stress level. The ratcheting strain obviously was produced in the first stage of cyclic deformation, and decreased with increasing strength of materials. Moreover, the ratcheting-strain rates of the harmonic-structured SUS316L steels were nearly stable in the secondary stage, which may indicate that the dislocation structure in the harmonic structure was stable under stress cycling [33].

The morphology of ratcheting-fatigue fracture surfaces of the harmonic-structured SUS316L steels are presented in Figure 5. It can be seen in Figure 5a that an obvious necking was observed in the ratcheting-fractured MMOh compact. This indicates that a large plastic deformation occurred before the fatigue fracture. In contrast, the fracture surface area of the MM10h compact and the MM30h compact was larger than that of the MMOh compact. As grain size decreased, the necking became insignificant. Therefore, this also showed that the accumulative plastic deformation became lower as the grain size decreased. Moreover, it can be seen in Figure 5 that the crack initiated from the specimen surface in the harmonic-structured SUS316L steels subjected to ratcheting-fatigue tests.
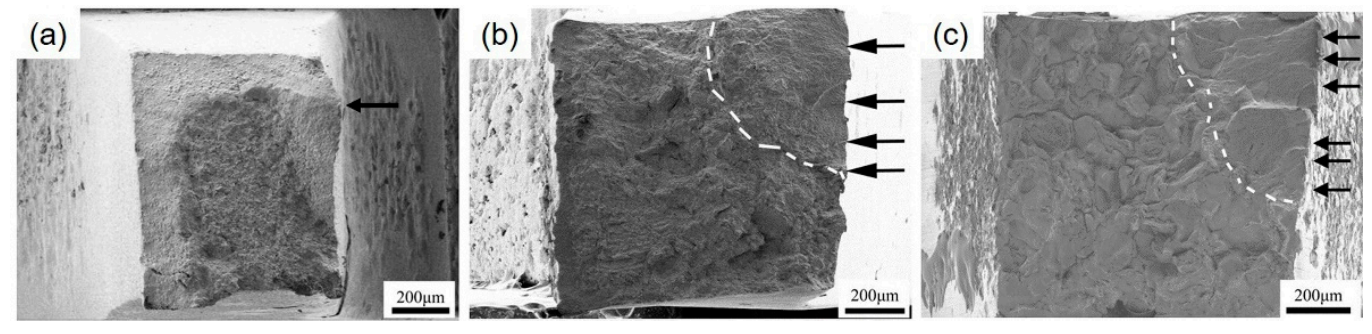

Figure 5. Morphology of ratcheting-fatigue fracture surface of harmonic-structured SUS316L steels: (a) MM0h compact; (b) MM10h compact; (c) MM30h compact.

As shown in Figures 4 and 5, the fatigue life was prolonged as the grain size decreased. It has been reported that ratcheting strain is produced from accumulative plastic deformation, which has detrimental effects on the fatigue life of materials [31]. In the present work, it is worthy to note that the ratcheting strain could be restrained in the harmonic-structured SUS316L steels due to their enhanced strength, which has great benefits for fatigue life. Therefore, it is thought that the harmonic-structure design could improve fatigue resistance under asymmetric stress cycling.

\subsection{Effects of Mean Stress on Ratcheting-Fatigue Behavior of Harmonic Structured SUS316L Steels}

As mentioned, the ratcheting strain increases with the increase of mean stress, which also affects fatigue life [29-31]. Therefore, the ratcheting behavior and fatigue life of the harmonic-structured SUS316L steels under the same stress amplitude $\left(\sigma_{a}=300 \mathrm{MPa}\right)$ but different mean stresses are presented in Figure 6. The results of ratcheting strain versus $N / \mathrm{N}_{f}$ for MM0h compact, MM10h compact, and MM30h compact are shown in Figure $6 \mathrm{~b}, \mathrm{~d}, \mathrm{f}$, respectively. As expected, an increased mean stress level brought about a higher ratcheting strain for harmonic-structured SUS316L steels. It can be seen from Figure $6 \mathrm{~b}$ that the ratcheting-strain rate of the MMOh compact was nearly zero in the secondary stage at $\sigma_{m}=300 \mathrm{MPa}$. In contrast, the stable ratcheting-strain rate increased 
at high stress levels. Both the ratcheting strain and ratcheting-strain rate increased as the mean stress increased from $300 \mathrm{MPa}$ to $450 \mathrm{MPa}$. As indicated in Figure 6d,f, the higher mean stress also induced the higher ratcheting strain for the MM10h compact and the MM30h compact. However, the variation in the ratcheting-strain rate in the stable region was not significant.
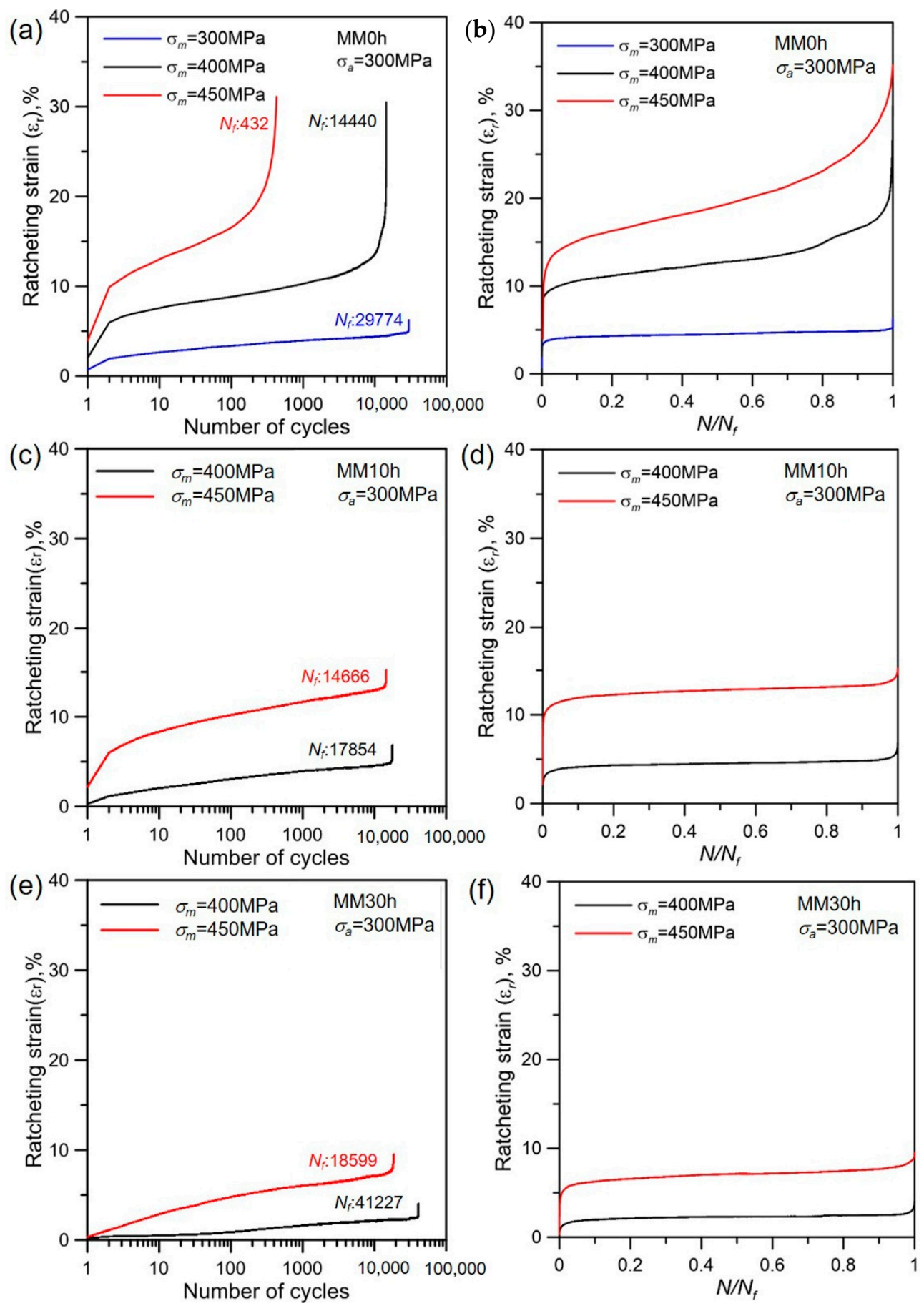

Figure 6. Effects of mean stress on fatigue life $(\mathbf{a}, \mathbf{c}, \mathbf{e})$ and ratcheting strain $(\mathbf{b}, \mathbf{d}, \mathbf{f})$ of harmonic-structured SUS316L steels: (a,b) MM0h compacts; (c,d) MM10h compacts; (e,f) MM30h compacts.

As expected, the increased mean stress produced a higher stress level, which promoted ratcheting-strain accumulation. The rapidly accumulative ratcheting strain was harmful for fatigue life. As indicated in Figure 6, the mean stress also played an important role in 
the ratcheting-fatigue life of harmonic-structured SUS316L steels subjected to asymmetric stress cycling. As the applied mean stress increased, the fatigue life decreased gradually. Therefore, the effects of mean stress on fatigue life need to be considered in fatiguelife prediction.

\subsection{Ratcheting-Fatigue-Life Prediction of Harmonic-Structured SUS316L Steels}

In the past decades, Basquin's equation has been used as a classical fatigue-lifeprediction model for fully reversed cyclic stress loading, as given in Equation (2) [28]:

$$
\sigma_{a}=\sigma_{f}^{\prime}\left(2 N_{f}\right)^{b}
$$

where $\sigma_{a}$ and $N_{f}$ are the stress amplitude and fatigue life, respectively. $\sigma_{f}^{\prime}$ is the fatigue strength coefficient, and $b$ is the fatigue exponent. However, if the mean stress is not zero, ratcheting strain could appear, which is harmful for fatigue life. Therefore, equivalent stress amplitude $\left(\sigma_{a}{ }^{e q}\right)$ has been proposed in many modified models for considering mean stress effects. As mentioned, the modified model based on the SWT criterion showed a higher prediction accuracy for ratcheting-fatigue life of materials performed under asymmetrical cyclic stress loading, as given in Equation (3):

$$
\sigma_{a}^{e q}=\sqrt{\sigma_{\max } \sigma_{a}}=\sigma_{a} \sqrt{1+\frac{\sigma_{m}}{\sigma_{a}}}=\sigma_{f}^{\prime}\left(2 N_{f}\right)^{b}
$$

where $\sigma_{\max }, \sigma_{m}$, and $\sigma_{a}$ are ultimate tensile strength, mean stress, and stress amplitude, respectively. In our previous work, a part of fatigue lives of harmonic-structured SUS316L steels were obtained under pulsating cyclic stress loading [24]. Although both mean stress and stress amplitude were changed in these experiments, the fatigue-life data can also be used to fit the parameters of the SWT fatigue-life-prediction model. Therefore, all fatigue life data under asymmetric stress cycling were used to analyze the fatigue life of the harmonic-structured SUS316L steels.

Figure 7 shows the relationship between equivalent stress amplitude based on the SWT criterion and fatigue life. Overall, the fatigue-life deviation of harmonic-structured SUS316L steels was significant. The fatigue life decreased with an increase of equivalent stress amplitude. Compared with the CG bulk SUS316L steels, the harmonic-structured SUS316L steels had a higher fatigue strength. The fatigue strength coefficient $\sigma_{f}^{\prime}$ and fatigue exponent $b$ in the SWT model are shown in Table 4. As indicated in Table 4, no appreciable influence of grain structure on $\sigma_{f}^{\prime}$ and $b$ was observed. Figure 8 shows the comparison between the observed and predicted fatigue life determined from parameters of the SWT model for the MMOh compact. Due to the large deviation in fatigue life, it is seen in Figure 8a that the fatigue lives of MMOh compacts were almost located in the 5 times error band. However, as shown in Figure 8b,c, the fatigue lives of the MM10h and MM30h compacts could not be predicted well using the same parameters of the MMOh compacts. Therefore, this indicated that the deviation of the fatigue life of harmonicstructured SUS316L steels was significant, and fatigue life was influenced significantly by grain structure. The parameters for the MM0h compacts were not suitable for the MM10h and MM30h compacts.

Table 4. Tensile strength and SWT parameters of harmonic-structured SUS316L steels.

\begin{tabular}{ccccc}
\hline Materials & $\begin{array}{c}\text { Yield Strength } \\
\sigma_{\boldsymbol{s}} \text { (MPa) }\end{array}$ & $\begin{array}{c}\text { Ultimate Tensile } \\
\text { Strength } \sigma_{\text {UTS }} \\
\text { (MPa) }\end{array}$ & $\begin{array}{c}\text { Fatigue } \\
\text { Strength } \\
\text { Coefficient } \sigma_{f^{\prime}}\end{array}$ & $\begin{array}{c}\text { Fatigue } \\
\text { Exponent } \boldsymbol{b}\end{array}$ \\
\hline MM0h & 512 & 721 & 681 & -0.046 \\
MM10h & 580 & 776 & 891 & -0.069 \\
MM30h & 675 & 794 & 735 & -0.041 \\
Bulk [24] & 315 & 607 & 499 & -0.073 \\
\hline
\end{tabular}




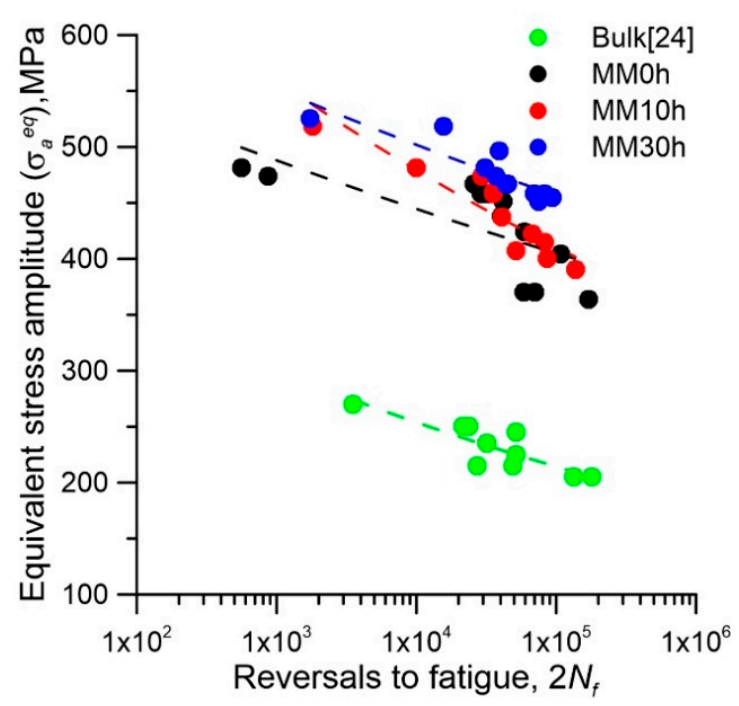

Figure 7. The dependence of the fatigue life $\left(2 N_{f}\right)$ on the equivalent stress amplitude $\left(\sigma_{a}^{e q}\right)$ of harmonic-structured 316LN steels.
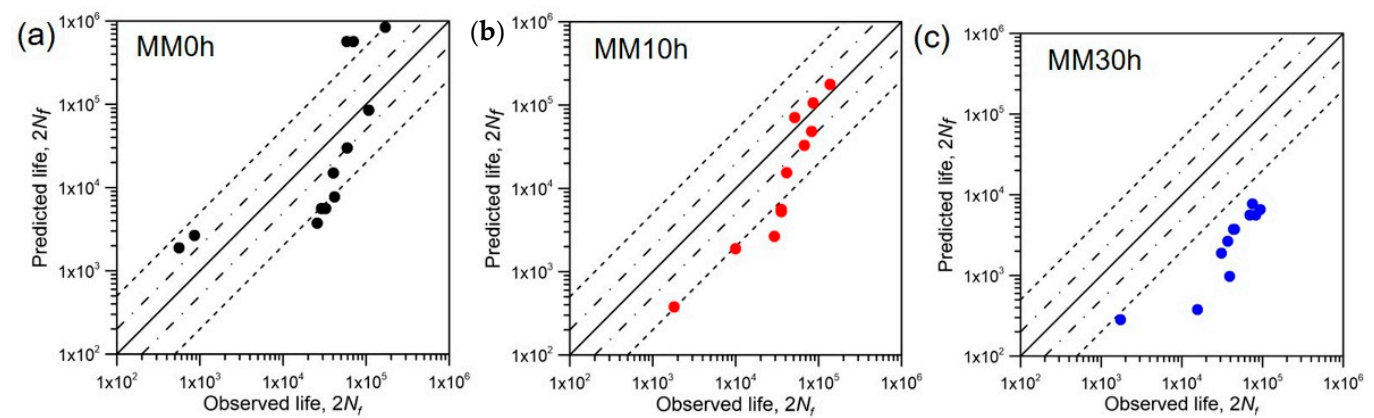

Figure 8. Comparison between observed life and predicted life based on the SWT fatigue-life-prediction model of harmonicstructured SUS316L steels: (a) MM0h compacts; (b) MM10h compacts; (c) MM30h compacts.

As mentioned, the strength of harmonic-structured SUS316L steels increased with increasing shell volume fraction, which also enhanced the fatigue resistance. Therefore, the strength variation caused by different grain sizes needs to be considered in fatiguelife prediction. To improve the response of grain structure on fatigue-life prediction of harmonic-structured SUS316L steels, a modified equivalent stress amplitude for the SWT criterion is proposed in Equation (4):

$$
\sigma_{a}^{e q *}=\sigma_{a}^{e q}\left(1-\frac{\sigma_{u}^{*}-\sigma_{u, M M 0 h}}{\sigma_{u, M M 0 h}}\right)
$$

where $\sigma_{a}^{e q}$ and $\sigma_{a}^{e q *}$ are the as-reserved equivalent stress amplitude determined by the SWT equation and the modified equivalent stress amplitude of the MM10h or MM30h compacts. $\sigma_{u}^{*}$ is the ultimate tensile strength of the MM10h compact or the MM30h compact. $\sigma_{u, M M 0 h}$ is the ultimate tensile strength of the MMOh compact. Therefore, by introducing the effect of the enhanced ultimate tensile strength into the SWT criterion, the fatigue-life-prediction model for the harmonic-structured SUS316L steels under asymmetric stress cycling is proposed in Equation (5). The same parameters $\sigma_{f}^{\prime}$ and $b$ for MM0h compacts are also used in the modified model:

$$
\sigma_{a}^{e q *}=\sigma_{a}^{e q}\left(1-\frac{\sigma_{u}^{*}-\sigma_{u, M M 0 h}}{\sigma_{u, M M 0 h}}\right)=\sigma_{f}^{\prime}\left(2 N_{f}\right)^{b}
$$


The comparison between observed fatigue life and predicted fatigue life determined by the modified model based on the SWT criterion is presented in Figure 9. As indicated in Figure 9b,c, most of the fatigue-life points of the harmonic-structured SUS316L steels were located in the 5 times error band. The predicted results for the MM10h compacts and MM30h compacts by the modified model was better than that predicted by the as-received SWT fatigue-life-prediction model.
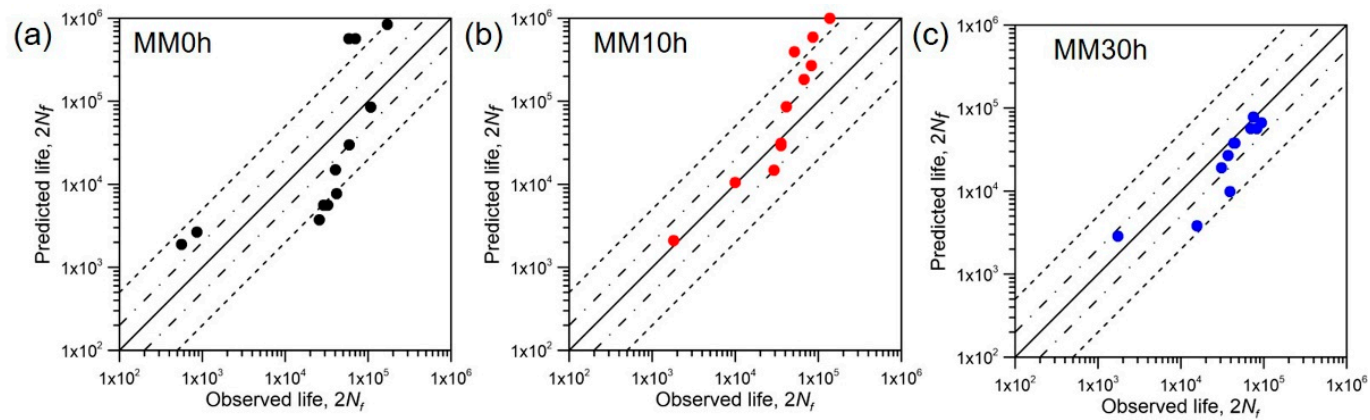

Figure 9. Comparison between observed life and predicted life based on the modified SWT fatigue-life-prediction model of harmonic-structured SUS316L steels: (a) MM0h compacts; (b) MM10h compacts; (c) MM30h compacts.

\section{Conclusions}

In the present work, the ratcheting-fatigue behavior of harmonic-structured SUS316L stainless steels was investigated under asymmetrical stress cycling at room temperature. The effects of grain structure and mean stress on ratcheting strain and fatigue life were analyzed. The main conclusions are summarized as follows:

(1) The ratcheting behavior of the harmonic-structured SUS316L steels subjected to under asymmetrical stress cycling was significant. The ratcheting strain was produced rapidly in the early stage of cyclic deformation, and became stable in the following stage. Finally, it increased near fatigue failure. The ratcheting-strain accumulation was highly influenced by grain structure and mean stress level. A lower grain size or higher mean stress tended to induce a higher ratcheting strain. The increased shell volume fraction enhanced the strength of materials, which restrained the ratchetingstrain accumulation under the same stress level.

(2) The ratcheting strain had detrimental effects on the fatigue life of the harmonicstructured SUS316L steels. A rapid ratcheting-strain accumulation caused a shorter fatigue life. As the shell volume fraction increased or mean stress decreased, the ratcheting strain was restricted, which prolonged the fatigue life.

(3) A proposed fatigue-life model based on the SWT criterion was employed to predict the fatigue life of the harmonic-structured SUS316L steels under asymmetrical stress cycling. The variation of ultimate tensile strength induced by grain refinement was considered in the modified fatigue-life-prediction model, which showed good predicting accuracy. Most of the fatigue-life points were located in the 5 times error band.

(4) Compared with homogeneous CG materials, the harmonic-structure-designed materials had a good balance of high strength and high ductility. Meanwhile, the method also had great benefits for improving fatigue resistance under asymmetrical stress cycling.

Author Contributions: Conceptualization, Z.Z. and K.A.; methodology, Z.Z.; software, Y.S.; validation, Z.Z.; formal analysis, Z.Z.; investigation, Z.Z.; resources, Y.S., H.M. and M.N.; data curation, Y.S. and H.M.; writing—original draft preparation, Y.S.; writing—review and editing, Z.Z. and M.O.K.; visualization, Z.Z.; supervision, Z.Z. and K.A.; project administration, Z.Z., M.O.K. and K.A.; funding acquisition, Z.Z. All authors have read and agreed to the published version of the manuscript. 
Funding: This work was partially supported by the National Key Research and Development Program of China (2018YFC0808600), and the National Natural Science Foundation of China (52075368, 51605325).

Institutional Review Board Statement: Not applicable.

Informed Consent Statement: Not applicable.

Data Availability Statement: Data is contained within the article.

Acknowledgments: The authors would like to thank Xu Chen and Chao Zhang (School of Chemical Engineering and Technology, Tianjin University) for their kind help in mechanical testing and modification of the fatigue-life-prediction model.

Conflicts of Interest: The authors declare no conflict of interest.

\section{References}

1. Kikuchi, S.; Nukui, Y.; Nakatsuka, Y.; Nakai, Y.; Nakatani, M.; Kawabata, M.O.; Ameyama, K. Effect of bimodal harmonic structure on fatigue properties of austenitic stainless steel under axial loading. Int. J. Fatigue 2019, 127, 222-228. [CrossRef]

2. Chadha, K.; Tian, Y.; Spray, J.G.; Aranas, C. Effect of Annealing Heat Treatment on the Microstructural Evolution and Mechanical Properties of Hot Isostatic Pressed 316L Stainless Steel Fabricated by Laser Powder Bed Fusion. Metals 2020, 10, 753. [CrossRef]

3. Zheng, R.; Liu, M.; Zhang, Z.; Ameyama, K.; Ma, C. Towards strength-ductility synergy through hierarchical micro-structure design in an austenitic stainless steel. Scr. Mater. 2019, 169, 76-81. [CrossRef]

4. Yuan, X.; Yu, W.; Fu, S.; Yu, D.; Chen, X. Effect of mean stress and ratcheting strain on the low cycle fatigue behavior of a wrought 316LN stainless steel. Mater. Sci. Eng. A 2016, 677, 193-202. [CrossRef]

5. Li, B.; Zheng, Y.; Shi, S.; Zhang, Z.; Chen, X. Cyclic deformation behavior and failure mechanism of S32205 duplex stainless steel under torsional fatigue loadings. Mater. Sci. Eng. A 2020, 786, 139443. [CrossRef]

6. Li, B.; Zheng, Y.; Shi, S.; Zhang, Z.; Chen, X. Cyclic deformation and cracking behavior of 316LN stainless steel under thermomechanical and isothermal fatigue loadings. Mater. Sci. Eng. A 2020, 773, 138866. [CrossRef]

7. Ueno, H.; Kakihata, K.; Kaneko, Y.; Hashimoto, S.; Vinogradov, A. Enhanced fatigue properties of nanostructured austenitic SUS 316L stainless steel. Acta Mater. 2011, 59, 7060-7069. [CrossRef]

8. Ovid'Ko, I.; Valiev, R.; Zhu, Y. Review on superior strength and enhanced ductility of metallic nanomaterials. Prog. Mater. Sci. 2018, 94, 462-540. [CrossRef]

9. Lei, Y.; Wang, Z.; Xu, J.; Lu, K. Simultaneous enhancement of stress- and strain-controlled fatigue properties in 316L stainless steel with gradient nanostructure. Acta Mater. 2019, 168, 133-142. [CrossRef]

10. Pan, Q.; Lu, L. Improved fatigue resistance of gradient nanograined metallic materials: Suppress strain localization and damage accumulation. Scr. Mater. 2020, 187, 301-306. [CrossRef]

11. Pan, Q.; Long, J.; Jing, L.; Tao, N.; Lu, L. Cyclic strain amplitude-dependent fatigue mechanism of gradient nanograined Cu. Acta Mater. 2020, 196, 252-260. [CrossRef]

12. Mine, Y.; Katashima, S.; Ding, R.; Bowen, P.; Takashima, K. Fatigue crack growth behaviour in single-colony lamellar structure of Ti-6Al-4V. Scr. Mater. 2019, 165, 107-111. [CrossRef]

13. Chakraborti, P.; Mitra, M. Room temperature low cycle fatigue behaviour of two high strength lamellar duplex ferrite?martensite (DFM) steels. Int. J. Fatigue 2005, 27, 511-518. [CrossRef]

14. Nalla, R.K.; Boyce, B.L.; Campbell, J.P.; Peters, J.O.; Ritchie, R.O. Influence of microstructure on high-cycle fatigue of Ti-6Al-4V: Bimodal vs. Lamellar structures. Metall. Mater. Trans. A 2002, 31A, 899-918. [CrossRef]

15. Koyama, M.; Zhang, Z.; Wang, M.; Ponge, D.; Raabe, D.; Tsuzaki, K.; Noguchi, H.; Tasan, C.C. Bone-like crack re-sistance in hierarchical metastable nanolaminate steels. Science 2017, 355, 1055-1057. [CrossRef] [PubMed]

16. Orlov, D.; Ameyama, K. Critical Assessment 37: Harmonic structure materials-Idea, status and perspectives. Mater. Sci. Tech-Lond. 2020, 36, 517-526. [CrossRef]

17. $\mathrm{Wu}, \mathrm{X}$; Z Zhu, Y. Heterogeneous materials: A new class of materials with unprecedented mechanical properties. Mater. Res. Lett. 2017, 5, 527-532. [CrossRef]

18. Zhang, Z.; Vajpai, S.K.; Orlov, D.; Ameyama, K. Improvement of mechanical properties in SUS304L steel through the control of bimodal microstructure characteristics. Mater. Sci. Eng. A 2014, 598, 106-113. [CrossRef]

19. Zhang, Z.; Orlov, D.; Vajpai, S.K.; Tong, B.; Ameyama, K. Importance of Bimodal Structure Topology in the Control of Mechanical Properties of a Stainless Steel. Adv. Eng. Mater. 2014, 17, 791-795. [CrossRef]

20. Vajpai, S.K.; Ota, M.; Watanabe, T.; Maeda, R.; Sekiguchi, T.; Kusaka, T.; Ameyama, K. The Development of High Performance Ti-6Al-4V Alloy via a Unique Microstructural Design with Bimodal Grain Size Distribution. Met. Mater. Trans. A 2015, 46, 903-914. [CrossRef]

21. Vajpai, S.K.; Sawangrat, C.; Yamaguchi, O.; Ciuca, O.P.; Ameyama, K. Effect of bimodal harmonic structure design on the deformation behavior and mechanical properties of Co-Cr-Mo alloy. Mater. Sci. Eng. C 2016, 58, 1008-1015. [CrossRef] [PubMed] 
22. Li, G.; Liu, M.; Lyu, S.; Nakatani, M.; Zheng, R.; Ma, C.; Li, Q.; Ameyama, K. Simultaneously enhanced strength and strain hardening capacity in FeMnCoCr high-entropy alloy via harmonic structure design. Scr. Mater. 2021, 191, 196-201. [CrossRef]

23. Dirras, G.; Ueda, D.; Hocini, A.; Tingaud, D.; Ameyama, K. Cyclic shear behavior of conventional and harmonic structuredesigned Ti-25Nb-25Zr $\beta$-titanium alloy: Back-stress hardening and twinning inhibition. Scr. Mater. 2017, 138, 44-47. [CrossRef]

24. Zhang, Z.; Ma, H.; Zheng, R.; Hu, Q.; Nakatani, M.; Ota, M.; Chen, G.; Chen, X.; Ma, C.; Ameyama, K. Fatigue be-havior of a harmonic structure designed austenitic stainless steel under uniaxial stress loading. Mater. Sci. Eng. A 2017, 707, 287-294. [CrossRef]

25. Zhou, G.; Ma, H.; Zhang, Z.; Sun, J.; Wang, X.; Zeng, P.; Zheng, R.; Chen, X.; Ameyama, K. Fatigue crack growth behavior in a harmonic structure designed austenitic stainless steel. Mater. Sci. Eng. A 2019, 758, 121-129. [CrossRef]

26. Kikuchi, S.; Mori, T.; Kubozono, H.; Nakai, Y.; Kawabata, M.O.; Ameyama, K. Evaluation of near-threshold fatigue crack propagation in harmonic-structured CP titanium with a bimodal grain size distribution. Eng. Fract. Mech. 2017, 181, 77-86. [CrossRef]

27. Kang, G. Ratchetting: Recent progresses in phenomenon observation, constitutive modeling and application. Int. J. Fatigue 2008, 30, 1448-1472. [CrossRef]

28. Lim, C.-B.; Kim, K.; Seong, J. Ratcheting and fatigue behavior of a copper alloy under uniaxial cyclic loading with mean stress. Int. J. Fatigue 2009, 31, 501-507. [CrossRef]

29. Lin, Y.; Chen, X.-M.; Chen, G. Uniaxial ratcheting and low-cycle fatigue failure behaviors of AZ91D magnesium alloy under cyclic tension deformation. J. Alloy. Compd. 2011, 509, 6838-6843. [CrossRef]

30. Paul, S.K.; Sivaprasad, S.; Dhar, S.; Tarafder, S. Ratcheting and low cycle fatigue behavior of SA333 steel and their life prediction. J. Nucl. Mater. 2010, 401, 17-24. [CrossRef]

31. Xia, Z.; Kujawski, D.; Ellyin, F. Effect of mean stress and ratcheting strain on fatigue life of steel. Int. J. Fatigue 1996, 18, 335-341. [CrossRef]

32. Zheng, R.; Zhang, Z.; Nakatani, M.; Ota, M.; Chen, X.; Ma, C.; Ameyama, K. Enhanced ductility in harmonic structure designed SUS316L produced by high energy ball milling and hot isostatic sintering. Mater. Sci. Eng. A 2016, 674, 212-220. [CrossRef]

33. Gaudin, C.; Feaugas, X. Cyclic creep process in AISI 316L stainless steel in terms of dislocation patterns and internal stresses. Acta Mater. 2004, 52, 3097-3110. [CrossRef] 